\title{
Variação temporal do fitoplâncton em três praias urbanas do litoral sul do estado de Pernambuco, Nordeste do Brasil
}

\author{
Leandro Cabanez Ferreira', ${ }^{1,3}$, Maria da Glória Gonçalves da Silva Cunha², Maria Luise Koeninge2, \\ Fernando Antônio do Nascimento Feitosa ${ }^{2}$, Marilene Felipe Santiago ${ }^{1}$ e Kátia Muniz ${ }^{2}$
}

Recebido em 17/01/2008. Aceito 21/09/2009

\begin{abstract}
RESUMO - (Variação temporal do fitoplâncton em três praias urbanas do litoral Sul de Pernambuco, Nordeste do Brasil). Este trabalho teve como objetivo efetuar uma análise comparativa da estrutura da comunidade fitoplanctônica, variação da biomassa e dados ambientais, na zona de arrebentação das praias arenosas de Brasília Formosa ( $\left.8^{\circ} 04^{\prime} \mathrm{S} ; 34^{\circ} 52^{\prime} \mathrm{W}\right)$, Boa Viagem ( $\left.8^{\circ} 07^{\prime} \mathrm{S} ; 34^{\circ} 53^{\prime} \mathrm{W}\right)$ e Piedade $\left(8^{\circ} 10^{\prime} \mathrm{S}\right.$; $\left.34^{\circ} 54^{\prime} \mathrm{W}\right)$ no litoral pernambucano. Amostras com garrafa e com rede foram coletadas durante o período chuvoso (maio, junho e julho/2005) e de estiagem (novembro, dezembro/2005 e janeiro/2006), simultaneamente com os dados ambientais (temperatura da água e do ar, salinidade, material em suspensão, nitrito, nitrato, fosfato, silicato, precipitação pluviométrica, velocidade e direção do vento). Do total de 119 táxons infragenéricos, as diatomáceas obtiveram maior representatividade, em termos de frequência e abundância, destacando-se Asterionellopsis glacialis (Castracane) Round, Bellerochea malleus (Brightwell) Van Heurck, Dactyliosolen fragilissimus (Bergon) Hasle, Helicotheca tamesis (Shrubsole) Ricard e Licmophora abbreviata Agardh. A. glacialis foi dominante durante o período chuvoso e H. tamesis durante o período de estiagem. Os resultados indicaram que as condições ambientais de cada período sazonal refletiram sobre a composição específica, clorofila $a$ e densidade total, propiciando florescimentos esporádicos $\left(2,3 \times 10^{6} \mathrm{cé}^{-} . \mathrm{L}^{-1}\right)$ no período de estiagem. A morfologia e o hidrodinamismo dos ambientes de praia analisados não favoreceram a formação de manchas por acumulação de microalgas.
\end{abstract}

Palavras-chave: praias arenosas, zona de arrebentação, clorofila $a$, diatomáceas, Asterionellopsis glacialis

\begin{abstract}
Phytoplankton temporal variation on three urban beaches of Pernambuco's South coast, Brazilian Northeast). This study aimed to make a comparative analysis of phytoplankton community structure, biomass variation and environmental data in the surf-zone of Brasilia Formosa $\left(8^{\circ} 04\right.$ 'S; $34^{\circ} 52^{\prime} \mathrm{W}$ ), Boa Viagem ( $8^{\circ} 07^{\prime} \mathrm{S} ; 4^{\circ} 53^{\prime} \mathrm{W}$ ) and Piedade ( $8^{\circ} 10^{\prime} \mathrm{S} ; 34^{\circ} 54^{\prime} \mathrm{W}$ ) sandy beaches, on the Pernambuco coast. Bottle and net samples were collected during the rainy season (May, June and July/2005) and the dry season (November, December/2005 and January/2006) with simultaneous environmental data collection (water temperature, salinity, suspended material, nitrite, nitrate, phosphate, silicate, rainfall, wind speed and direction). Among the 119 infrageneric taxa identified, diatoms were the most representative group regarding abundance and frequency, notably Asterionellopsis glacialis (Castracane) Round, Bellerochea malleus (Brightwell) Van Heurck, Dactyliosolen fragilissimus (Bergon) Hasle, Helicotheca tamesis (Shrubsole) Ricard and Licmophora abbreviata Agardh. A. glacialis was dominant in the rainy season while H. tamesis was more numerous in the dry one. Study results indicate that specific composition, chlorophyll $a$ and total density evidenced the seasonal environmental conditions, with occasional blooms $\left(2.3 \times 10^{6}\right.$ cells. $\left.L^{-1}\right)$ in the dry season. Morphology and hydrodynamics were unfavorable to the formation of microalgae patches.
\end{abstract}

Key words: sandy beaches, surf zone, chlorophyll $a$, diatoms, Asterionellopsis glacialis

\section{Introdução}

Nos últimos anos, as perturbações antrópicas (poluição orgânica, industrial e construções à beira mar que alteram a linha de costa) ou naturais (frentes frias, aumento da vazão de rios próximos, mudanças na direção dos ventos, etc.), vêm afetando os ecossistemas marinhos, causando visíveis modificações no desenvolvimento, sobrevivência e dispersão dos organismos do fitoplâncton, selecionando uma biota adaptada com complexos padrões de distribuição espacial e temporal (Harris 1986; Rörig et al. 2006).

As praias brasileiras ainda são pouco estudadas mesmo existindo grande atividade biológica local (Margem et al. 2003). Nestes ecossistemas, populações de microalgas abastecem numerosas cadeias alimentares e comumente são acumuladas na superfície formando manchas (Talbot et al. 1990). Até agora, as investigações sobre o fitoplâncton da zona de arrebentação de praias arenosas se concentraram no Sul do Brasil, sendo que a maioria investiga os processos formadores das acumulações (Odebrecht et al. 1995; Odebrecht \& Abreu 1997; Rezende \& Brandini 1997; Rörig et al. 1997; Rörig \& Garcia 2003).

No litoral pernambucano estes trabalhos são escassos apresentando uma abordagem qualitativa, com as primeiras contribuições realizadas no litoral sul por Eskinazi \& Satô (1963/64), na praia de Piedade, identificando 52 espécies de diatomáceas e Satô et al. (1963/64), na praia de Tamandaré, onde registraram um evento de floração associado à cianofícea Oscillatoria (Trichodesmium) erythraeum Ehrenberg. Pereira et al. (2005), em áreas abrigadas ao longo das praias de Casa Caiada e Rio Doce (litoral norte), realizaram um estudo sobre a estrutura das comunidades planctônicas.

Neste contexto, este trabalho representa a primeira contribuição quali-quantitativa do fitoplâncton em zona de arrebentação de praias arenosas do Nordeste Brasileiro com o objetivo de efetuar uma análise comparativa da estrutura da comunidade, variação de biomassa e parâmetros ambientais, durante o período chuvoso e de estiagem nas praias de Brasília Formosa, Boa Viagem e Piedade situadas na região metropolitana do Recife (PE).

\section{Material e métodos}

As praias de Brasília Formosa, Boa Viagem e Piedade estão situadas na região metropolitana do Recife no estado de Pernambuco, Nordeste do Brasil (Fig. 1). É uma área de hidrodinâmica complexa devido à presença de várias linhas de recifes de arenito e morfologia praial com estreita zona de arrebentação (aproximadamente 50 metros). Segundo a classificação

\footnotetext{
1 Universidade Federal de Pernambuco, Programa de Pós-Graduação em Oceanografia, Recife, PE, Brasil

Universidade Federal de Pernambuco, Departamento de Oceanografia, Recife, PE, Brasil

Autor para contato: leocabanez@yahoo.com.br
} 


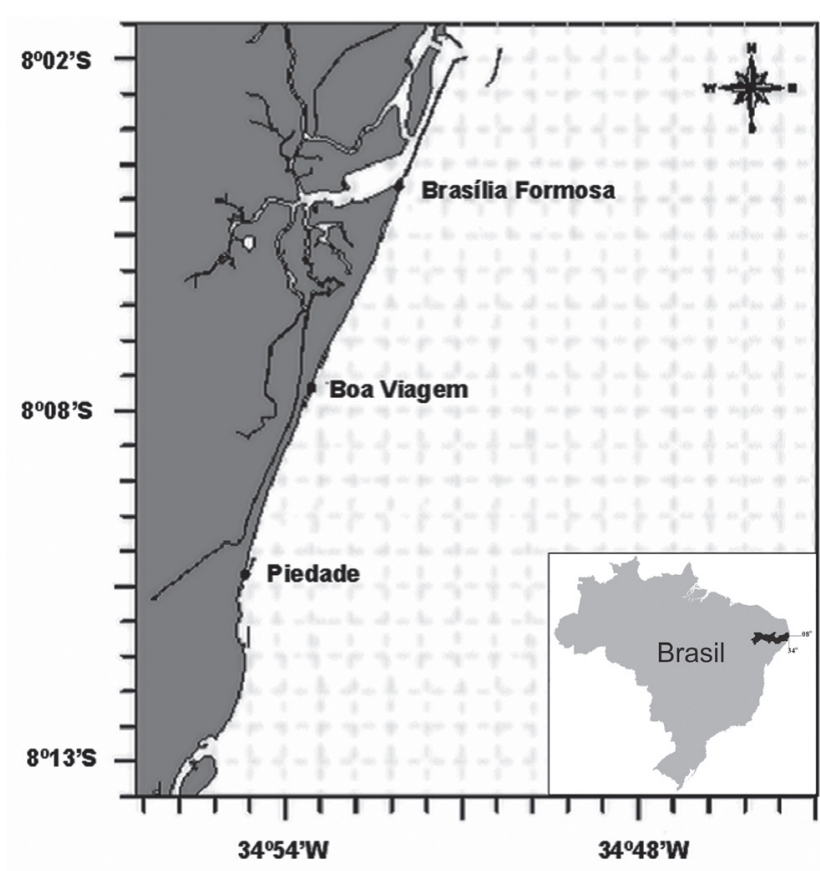

Figura 1. Localização da área de estudo.

de Köppen a região caracteriza-se por apresentar um clima tipo Ams', ou seja, tropical úmido, com uma precipitação pluviométrica anual que chega a $2000 \mathrm{~mm}$. A temperatura do ar é elevada, variando entre 22 e $26^{\circ} \mathrm{C}$ e uma umidade relativa do ar média anual oscilando entre 50 a $90 \%$. Predominam ventos com velocidades médias entre 6,1 e 9,3 nós, vindos principalmente do leste, no período de outubro a março e sul-sudeste, no período de abril a setembro (Aragão 2004).

A praia de Brasília Formosa está situada no bairro de Brasília Teimosa, local que sofreu uma grande obra de urbanização e se encontra em avançado estado de erosão costeira. Encontra-se próximo ao porto do Recife e bacia do Pina, recebendo descargas de indústrias e efluentes domésticos (Nascimento et al. 2003). Possui uma praia com areia fina onde, em alguns locais, não faz contato com o mar, devido à construção de um muro de contenção.

Boa Viagem é uma praia movimentada com grande fluxo turístico, forte especulação imobiliária e amplo comércio informal na orla. Apresenta areia de granulometria fina, quartzosa, com presença de dunas frontais vegetadas. As ondas têm alturas entre 0,6 a $1 \mathrm{~m}$, período de 5 a $7,8 \mathrm{~s}$ e altura máxima de 1,5 a 2,3 m (Rollnic \& Medeiros 2006). Segundo Manso et al. (dados não publicados) as correntes litorâneas são ausentes na maior parte do ano, favorecidos por ventos perpendiculares à costa e a tendência frontal da incidência das ondas. Quando ocorrem, as correntes apresentam-se preferencialmente no sentido Norte - Sul.

A praia de Piedade possui características muito parecidas com a praia de Boa Viagem. Está localizada próxima a foz do estuário de Barra de Jangadas, cuja contribuição terrígeno-fluvial apresenta provável influência sobre a produtividade das comunidades da zona costeira ao norte. Este estuário é um dos mais poluídos da Região Metropolitana do Recife, com indústrias químicas, de açúcar e álcool, metalúrgica, têxtil, alimentar e de bebidas, além dos elevados índices de contaminação bacteriológica (Branco 2008).

As marés que atuam em Pernambuco são do tipo mesomaré, dominadas por ondas e sob ação constante dos ventos alísios. Os valores representativos da altura da maré são de 2,4 m para sizígia máxima e 2,1 m para quadratura máxima. São do tipo semidiurna, com período médio de 12,42 horas, apresentando duas preamares e duas baixa-mares por dia lunar (Knoppers et al. 2002)

As coletas foram realizadas em maio, junho e julho de 2005 (período chuvoso) e em novembro e dezembro de 2005 e janeiro de 2006 (período de estiagem), em um ponto de amostragem em cada praia durante a baixamar e preamar de um mesmo dia. Medidas de temperatura e salinidade da água foram obtidas in situ, respectivamente, com termômetro de mercúrio e refratômetro manual. As amostras de água destinadas às análises das variáveis hidrobiológicas $(\mathrm{pH}$, material particulado em suspensão, nitrito, nitrato, fosfato, silicato e clorofila $a$ ) e contagem do número de células do fitoplâncton foram coletadas com garrafa de Kitahara. Para todas as análises, exceto do fitoplâncton, foram seguidas as orientações descritas em Strickland \& Parsons (1972) e Grasshoff et al. (1983).

As amostras de água destinadas à análise quali-quantitativa (riqueza de espécies e densidade celular) do fitoplâncton foram fixadas imediatamente com formol a 4\% (Newell \& Newell 1963). Sub-amostras de $10 \mathrm{~mL}$ foram analisadas pelo método de Utermöhl (1958) sob o aumento de 450x em microscópio invertido WILD M-40 e os resultados expressos em células por litro. Para a complementação do inventário florístico foram efetuados arrastos horizontais na superfície com rede de $45 \mu \mathrm{m}$ e a análise realizada em lâminas de Sedgwick-Rafter com alíquotas de 1,0 mL (Hasle 1978; Ferrario et al. 1995).

Para o enquadramento dos táxons foi utilizado o sistema de classificação proposto por Hoek et al. (1995).

Para interpretação da abundância relativa foram utilizadas as categorias dominantes para valores acima de $50 \%$ e abundantes para os valores superiores à média (Lobo \& Leighton 1986).

Em função do valor da freqüência, os táxons foram classificados em ocorrência muito freqüente $(>70 \%)$, freqüente $(70 \mid-40 \%)$, pouco freqüente $(40 \mid-10 \%)$ e esporádica $(\leq 10 \%)$.

Com os dados obtidos na análise quantitativa da comunidade fitoplanctônica foi estimado o índice de Diversidade específica (H') baseada em Shannon (1948), onde os resultados foram classificados, segundo Margalef (1978), em alta diversidade $\left(5 \mid-2,5\right.$ bits.cel $\left.^{-1}\right)$, baixa diversidade $(2,5 \mid-1$ bit.cel $\left.{ }^{-1}\right)$ e diversidade muito baixa $\left(\leq 1\right.$ bit.cel $\left.^{-1}\right)$.

Para identificar diferenças significativas $(\mathrm{p}<0,05)$ entre as praias, os meses de coleta e as marés, o teste não paramétrico de Kruskal-Wallis (BioEstat 3.0) foi aplicado sobre as variáveis físicas, químicas e biológicas.

Para a análise de agrupamento, os dados utilizados foram baseados na abundância relativa e freqüência de ocorrência, das espécies dominantes e freqüentes, aplicando-se o coeficiente de dissimilaridade de Bray \& Curtis (1957). A classificação utilizada foi a aglomeração hierárquica pelo método de ligação do peso proporcional (Weighted Pair Group Method Average Arithmetic - WPGMA). Realizou-se uma análise cofenética, cujo valor $>0,8$ foi considerado bem ajustado (Rohlf \& Fisher 1968).

A análise dos componentes principais (ACP) foi realizada no programa NTSYSpc 2.10t correlacionando uma matriz de dados biológicos (espécies dominantes, muito frequentes, clorofila $a$ e densidade total) e os parâmetros ambientais, através do coeficiente de Pearson.

\section{Resultados}

O valor acumulado da precipitação pluviométrica referente ao dia da coleta variou entre $10,5 \mathrm{~mm}$ (novembro de 2005) e $490 \mathrm{~mm}$ (junho de 2005). A temperatura do ar oscilou entre $21,0^{\circ} \mathrm{C}$ (julho de 2005 ) e $32,5^{\circ} \mathrm{C}$ (janeiro de 2006), com temperaturas na preamar acima das encontradas na baixa$\operatorname{mar}\left(29,4 \pm 2,2{ }^{\circ} \mathrm{C}\right.$ e $24,3 \pm 2,5^{\circ} \mathrm{C}$, respectivamente) (Fig. 2).

A intensidade dos ventos durante o período de estudo variou de 0 a 7,4 m.s. $\mathrm{s}^{-1}$, com os ventos mais fortes registrados nas preamares do período de estiagem. Os ventos de direção sul-sudeste foram mais freqüentes $(75 \%)$, principalmente durante o período de estiagem em ambas as marés (Fig. 3).

Não foi possível observar uma variação espacial significativa em nenhum dos parâmetros hidrobiológicos abordados nesse estudo, mostrando que as praias arenosas estudadas compartilham características semelhantes.

A temperatura da água variou de 27,9 a $32,8^{\circ} \mathrm{C}$ sendo o valor mínimo encontrado em julho de 2005, e o máximo em novembro de 2005 (Fig. 4A). Com relação à salinidade, os valores oscilaram entre 21,0 e 37,0 (junho de 2005 e janeiro de 2006, respectivamente). Não houve diferença significativa 


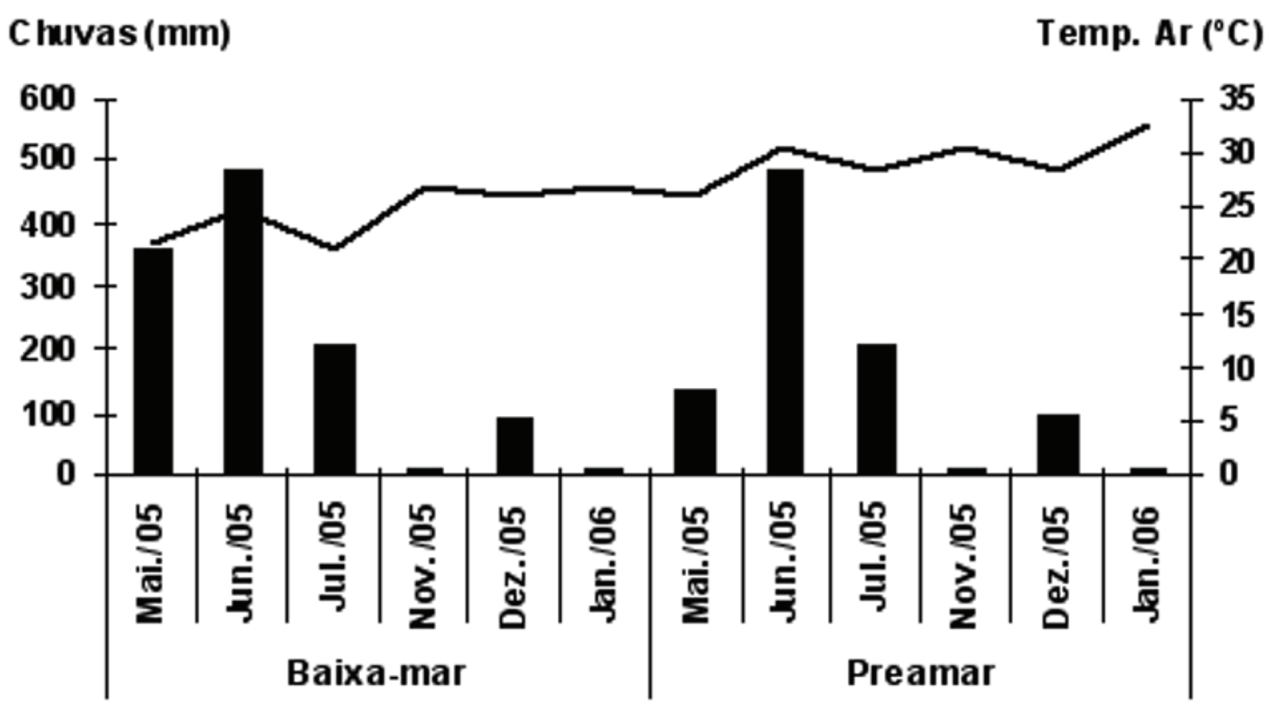

Figura 2. Variação sazonal da temperatura do ar e regime pluviométrico nas praias de Brasília Formosa, Boa Viagem e Piedade durante a baixa-mar (BM) e preamar (PM) do período chuvoso (maio, junho e julho/05) e de estiagem (novembro, dezembro/05 e janeiro/06).

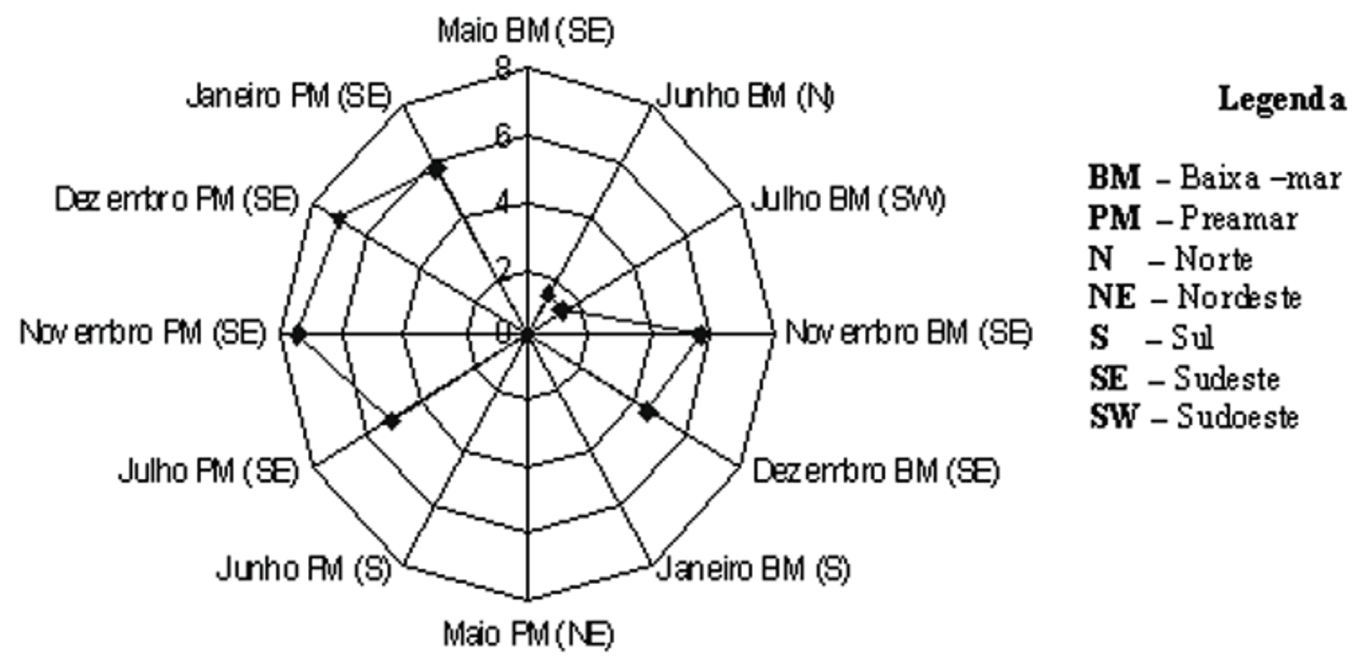

Figura 3. Variação da velocidade e direção do vento nas praias de Brasília Formosa, Boa Viagem e Piedade durante a baixa-mar (BM) e preamar (PM) do período chuvoso (maio, junho e julho/05) e de estiagem (novembro, dezembro/05 e janeiro/06).

( $>0,05)$ entre os períodos de chuva e estiagem, para estes parâmetros (Fig. 4B).

As concentrações do material particulado em suspensão na água tiveram um mínimo de $30 \mathrm{mg} . \mathrm{L}^{-1}$ registrado em julho de 2005 e um máximo de $160 \mathrm{mg} . \mathrm{L}^{-1} \mathrm{em}$ novembro de 2005. Sazonalmente, observou-se uma diferença $(p<0,02)$ deste parâmetro apenas na praia de Brasília Formosa (Fig. 4C).

O nitrogênio (nitrito + nitrato) apresentou concentrações que variaram de $0,14 \mu \mathrm{M}$ em janeiro de 2006 a 22,09 $\mu \mathrm{M}$ em junho de 2005 (Fig. 4D). Foi observada uma variação sazonal significativa $(\mathrm{p}<0,05)$ em Brasília Formosa, Boa Viagem e Piedade, com os maiores valores registrados no período chuvoso. Com relação ao fosfato e silicato (Fig. $4 \mathrm{E}$ e $\mathrm{F}$ ), as menores concentrações foram encontradas em julho e novembro de 2005, respectivamente, enquanto as maiores, em junho de 2005. Mesmo não ocorrendo variação sazonal significativa para fosfato e silicato, percebe-se que as maiores concentrações estão associadas ao período chuvoso.

A clorofila $a$ oscilou ao longo do ano apresentando um valor mínimo de 1,55 mg.m $\mathrm{m}^{-3}$ (baixa-mar; Brasília Formosa) em maio de 2005 e máximo de 33,54 mg.m ${ }^{-3}$ (preamar; Piedade) em janeiro de 2006 (Fig. 5). Com relação aos períodos do ano, ocorreram diferenças significativas $(\mathrm{p}<0,05)$ em Brasília Formosa, Boa Viagem e Piedade, com maiores valores de clorofila $a$ no período de estiagem. Apesar de não ocorrer variação espacial significativa, constatou-se maior média de biomassa na praia de Piedade $\left(9,02 \pm 9,26 \mathrm{mg} \cdot \mathrm{m}^{-3}\right)$, seguido de Brasília Formosa $\left(7,06 \pm 5,17\right.$ mg. $\left.\mathrm{m}^{-3}\right)$ e Boa Viagem $\left(6,08 \pm 3,38 \mathrm{mg} \cdot \mathrm{m}^{-3}\right)$. 

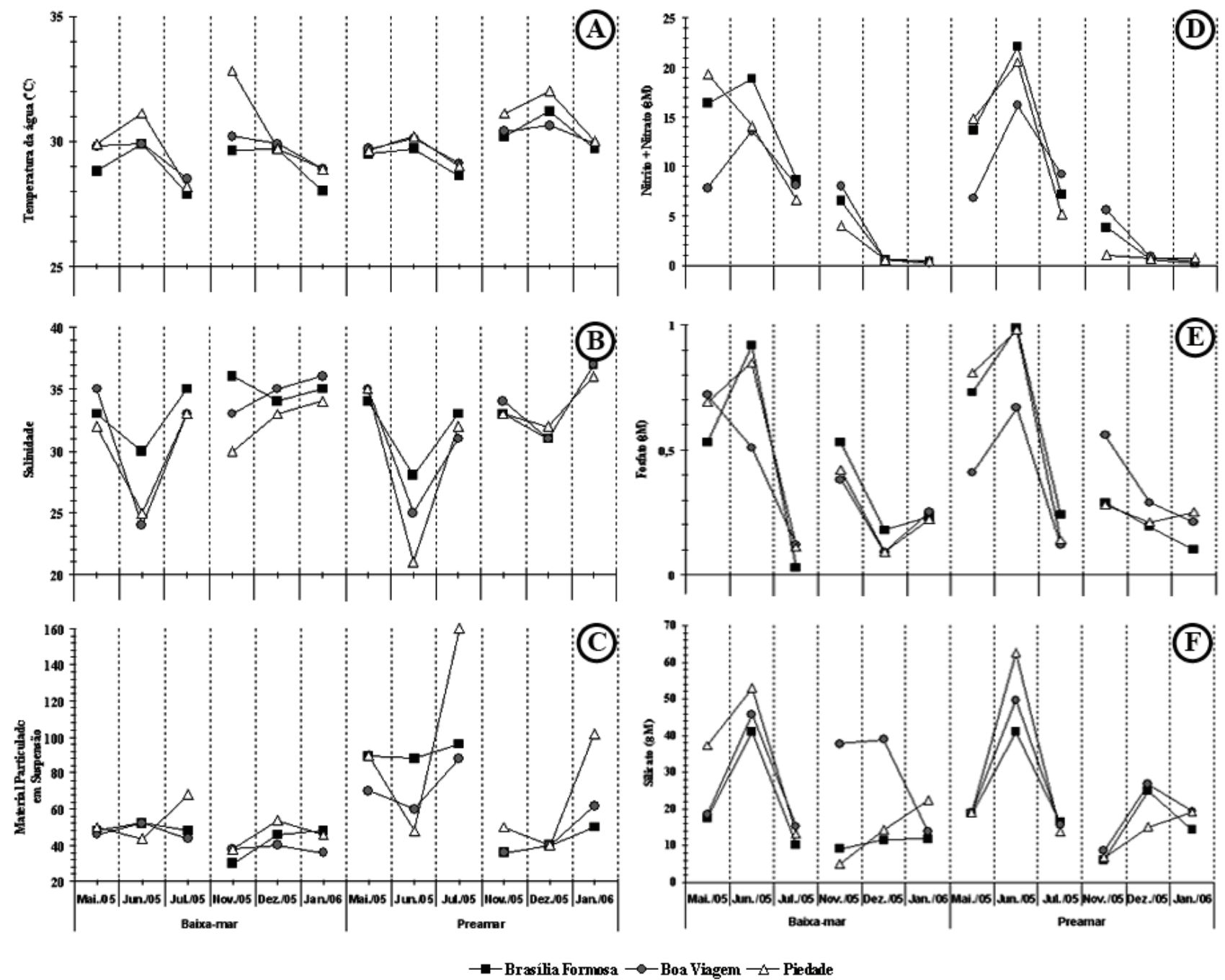

Figura 4. Variação da temperatura da água (A), salinidade (B), material particulado em suspensão (C), nitrogênio (nitrito + nitrato) (D), fosfato (E) e silicato (F) nas praias de Brasília Formosa, Boa Viagem e Piedade, durante a baixa-mar (BM) e preamar (PM) do período chuvoso (maio, junho e julho/05) e de estiagem (novembro, dezembro/05 e janeiro/06).

A densidade fitoplanctônica total apresentou um valor mínimo de 4,5 x $10^{4}$ céls. $L^{-1}$ (baixa-mar; Piedade) em junho de 2005 e um máximo de $2,3 \times 10^{6}$ céls.L.-1 (baixamar; Brasília Formosa) em dezembro de 2005. Apresentou diferenças significativas $(p<0,05)$ entre as estações do ano em Boa Viagem e Piedade, com densidades mais elevadas no período de estiagem.

Foram identificados 119 táxons (92 espécies) (Tab. 1), distribuídos em seis divisões: Heterokontophyta $(77,42 \%)$, Dinophyta $(9,68 \%)$, Chlorophyta $(8,87 \%)$, Cyanophyta $(2,42 \%)$ e Euglenophyta $(1,61 \%)$.

As diatomáceas que se destacaram como dominantes e muito frequentes foram: Asterionellopsis glacialis, Bellerochea malleus, Cerataulina pelagica, Chaetoceros brevis, Chaetoceros compressus, Chaetoceros lorenzianus, Cylindrotheca closterium, Dactyliosolen fragilissimus, Grammatophora marina, Guinardia striata, Helicotheca tamesis, Licmophora abbreviata, Plagiogramma sp., Odontella aurita var. obtusa, Pseudo-nitzschia sp. e Thalassionema nitzschioides.

A espécie dominante no período chuvoso foi Asterionellopsis glacialis, com picos de 83,28 e 82,72\% (de 972 e 1.507 células contadas, respectivamente) nas preamares de Brasília Formosa (maio de 2005) e de Piedade (junho de 2005), dominando todo mês de junho de 2005, em ambas as marés. Bellerochea malleus obteve apenas um pico de abundância ( $81,60 \%$ de 413 células) na preamar de Piedade (maio de 2005), sendo pouco abundante no resto do período.

No período de estiagem, Helicotheca tamesis foi dominante no mês de dezembro de 2005 com picos de 91,25 e $94,68 \%$ (de 7295 e 5712 células contadas, respectivamente) na praia de Boa Viagem em ambas as marés exceto na baixa-mar de Piedade, onde ocorreu a dominância de Licmophora abbreviata com $89,67 \%$ de 426 células. Asterionellopsis glacialis obteve $57,94 \%$ (de 1.284 células) em Boa Viagem na preamar, mas foi pouco abundante durante o resto do período. 


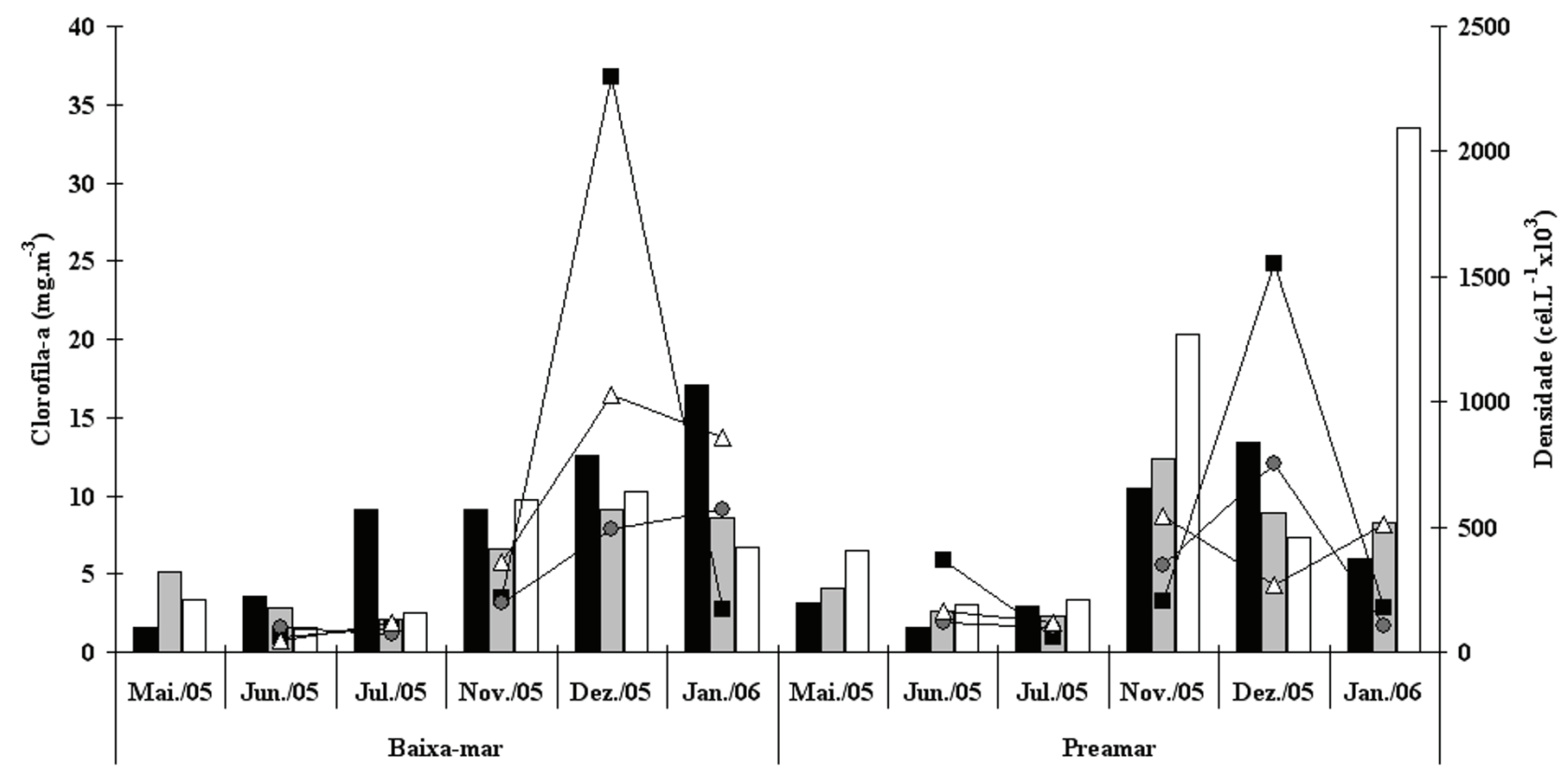

Baixa-mar

Clorofila $a$
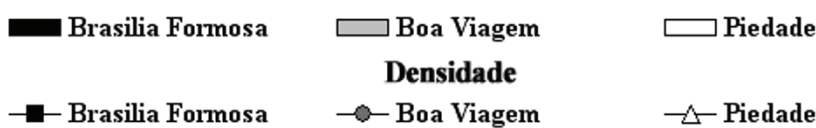

Figura 5. Variação da clorofila $a$ e densidade fitoplanctônica nas praias de Brasília Formosa, Boa Viagem e Piedade, durante a baixa-mar (BM) e preamar (PM) do período chuvoso (maio, junho e julho/05) e de estiagem (novembro, dezembro/05 e janeiro/06).

Tabela 1. Táxons identificados nas praias de Brasília Formosa, Boa Viagem e Piedade, Pernambuco, Brasil, durante o período chuvoso (maio, jun. e jul./05) e período de estiagem (nov., dez/05 e jan./06).

$\mathrm{MT}=$ muito freqüente $(>70 \%), \mathrm{F}=$ freqüente $(70 \mid-40 \%), \mathrm{PF}=$ pouco freqüente $(40 \mid-10 \%), \mathrm{E}=$ esporádico $(<10 \%), \mathrm{D}=\mathrm{Dulciaqüicola}, \mathrm{ES}=\mathrm{Estuarino}, \mathrm{N}=$ Nerítico, $\mathrm{O}=$ Oceânico e $\mathrm{T}$ = Ticoplanctônico.

\begin{tabular}{|c|c|c|c|c|c|}
\hline Táxons & $\begin{array}{l}\text { Classe de } \\
\text { Freqüência }\end{array}$ & Ecologia & Táxons & $\begin{array}{l}\text { Classe de } \\
\text { Freqüência }\end{array}$ & Ecologia \\
\hline CYANOPHYTA & & & Grammatophora sp. & $\mathrm{E}$ & --- \\
\hline Microcystis aeruginosa Brébisson & $\mathrm{PF}$ & $\mathrm{D}$ & Guinardia flaccida (Castracane) H. Péragallo & $\mathrm{PF}$ & $\mathrm{N}$ \\
\hline Microcystis wesenbergii (Komárek) Komárek & $\mathrm{E}$ & $\mathrm{D}$ & Guinardia striata (Stolterfoth) Hasle & PF & $\mathrm{N}$ \\
\hline Oscillatoria sp. & $\mathrm{E}$ & --- & Helicotheca tamesis (Shrubsole) Ricard & MF & $\mathrm{N}$ \\
\hline EUGLENOPHYTA & & & Hemiaulus membranaceus Cleve & $\mathrm{E}$ & $\mathrm{O}$ \\
\hline Euglena sp. & $\mathrm{PF}$ & --- & Leptocylindrus danicus Cleve & $\mathrm{PF}$ & $\mathrm{N}$ \\
\hline Trachelomonas sp. & E & --- & Licmophora abbreviata Agardh & MF & $\mathrm{T}$ \\
\hline DINOPHYTA & & & Licmophora sp. & $\mathrm{E}$ & --- \\
\hline Ceratium furca (Ehr.) Clap. e Lachmann & $\mathrm{E}$ & $\mathrm{N}$ & Lyrella lyra (Ehrenberg) Karayeva & $\mathrm{E}$ & $\mathrm{T}$ \\
\hline Ceratium spp. & $\mathrm{PF}$ & --- & Mastogloia splendida (Greg.) Cleve & $\mathrm{E}$ & $\mathrm{T}$ \\
\hline Protoperidinium venustum (Matzenauer) Balech & $\mathrm{E}$ & $\mathrm{O}$ & Melosira moniliformis (Müller) Agardh & $\mathrm{PF}$ & $\mathrm{T}$ \\
\hline Protoperidinium conicum (Gran) Balech & $\mathrm{PF}$ & $\mathrm{O}$ & Melosira nummuloides Agardh & PF & $\mathrm{T}$ \\
\hline Protoperidinium spp. & $\mathrm{F}$ & --- & Nitzschia longissima (Brèbisson) Grunow & $\mathrm{E}$ & $\mathrm{T}$ \\
\hline Pyrophacus horologicum Stein & $\mathrm{PF}$ & $\mathrm{O}$ & Nitzschia sigma (Kutzing) Wm. Smith & $\mathrm{PF}$ & $\mathrm{T}$ \\
\hline Pyrophacus steinii (Schiller) Wall e Dale & $\mathrm{E}$ & $\mathrm{O}$ & Nitzschia sp. & $\mathrm{E}$ & --- \\
\hline Pyrophacus sp. & $\mathrm{PF}$ & --- & Odontella aurita (Lyngb.) Agardh & $\mathrm{PF}$ & $\mathrm{T}$ \\
\hline BACILLARIOPHYTA & & & Odontella aurita var. obtusa (Kütz.) Moreno et al. & $\mathrm{F}$ & $\mathrm{T}$ \\
\hline Achnanthes brevipes Agardh & $\mathrm{E}$ & $\mathrm{T}$ & Odontella longicruris (Greville) Holan & $\mathrm{PF}$ & $\mathrm{N}$ \\
\hline Achnanthes longipes Agardh & E & $\mathrm{T}$ & Odontella mobiliensis (Bailey) Grunow & $\mathrm{PF}$ & $\mathrm{N}$ \\
\hline Achnanthes sp. & $\mathrm{E}$ & --- & Odontella regia (M. Schultze) R. Simonsen & $\mathrm{E}$ & $\mathrm{O}$ \\
\hline Actinoptychus senarius (Ehr.) Ehrenberg & E & $\mathrm{N}$ & Odontella tridens (Ehrenberg) Ehrenberg & $\mathrm{PF}$ & $\mathrm{T}$ \\
\hline Asterionellopsis glacialis (Castracane) Round & MF & $\mathrm{T}$ & Paralia sulcata (Ehrenberg) Cleve & $\mathrm{F}$ & $\mathrm{T}$ \\
\hline Aulacodiscus kittoni Arnot & E & $\mathrm{T}$ & Plagiogramma sp. & MF & --- \\
\hline
\end{tabular}


Tsbela 1. Continuação.

\begin{tabular}{|c|c|c|c|c|c|}
\hline Táxons & $\begin{array}{c}\text { Classe de } \\
\text { Freqüência }\end{array}$ & Ecologia & Táxons & $\begin{array}{c}\text { Classe de } \\
\text { Freqüência }\end{array}$ & Ecologia \\
\hline Bacillaria paxillifera (O. F. Müller) Hendey & $\mathrm{E}$ & $\mathrm{O}$ & Pleurosigma sp. & $\mathrm{PF}$ & --- \\
\hline Bacteriastrum delicatulum Cleve & $\mathrm{PF}$ & $\mathrm{O}$ & Podocystis adriatica Kützing & $\mathrm{PF}$ & $\mathrm{T}$ \\
\hline Bacteriastrum hyalinum Lauder & $\mathrm{PF}$ & $\mathrm{N}$ & Proboscia alata (Brightwell) Sundström & $\mathrm{PF}$ & $\mathrm{O}$ \\
\hline Bellerochea malleus (Brightwell) Van Heurck & $\mathrm{F}$ & $\mathrm{N}$ & Psammodictyon sp. & $\mathrm{E}$ & --- \\
\hline Biddulphia biddulphiana Smith & $\mathrm{F}$ & $\mathrm{T}$ & Pseudo-nitzschia sp. & $\mathrm{F}$ & --- \\
\hline Biddulphia dubia (Brightwell) Cleve & $\mathrm{E}$ & $\mathrm{T}$ & Rhabdonema adriaticum Kutzing & $\mathrm{PF}$ & $\mathrm{T}$ \\
\hline Campylodiscus sp. & $\mathrm{E}$ & --- & Rhizosolenia robusta Norman & $\mathrm{E}$ & $\mathrm{O}$ \\
\hline Campyloneis grevillei (Smith) Grunow & $\mathrm{PF}$ & $\mathrm{T}$ & Rhizosolenia setigera Brightwell & $\mathrm{F}$ & $\mathrm{O}$ \\
\hline Cerataulina pelagica (Cleve) Hendey & $\mathrm{PF}$ & $\mathrm{N}$ & Rhizosolenia styliformis Brightwell & $\mathrm{PF}$ & $\mathrm{O}$ \\
\hline Cerataulus turgidus Ehrenberg & $\mathrm{E}$ & $\mathrm{T}$ & Stauropsis membranacea (Cleve) Meunier & $\mathrm{E}$ & $\mathrm{N}$ \\
\hline Chaetoceros affinis Lauder & $\mathrm{PF}$ & $\mathrm{O}$ & Streptotheca sp. & $\mathrm{E}$ & --- \\
\hline Chaetoceros atlanticus Cleve & $\mathrm{PF}$ & $\mathrm{O}$ & Striatella unipunctata (Lyngbye) Agardh & $\mathrm{E}$ & $\mathrm{T}$ \\
\hline Chaetoceros brevis Schütt & $\mathrm{PF}$ & $\mathrm{N}$ & Surirella fastuosa Ehrenberg & $\mathrm{E}$ & $\mathrm{T}$ \\
\hline Chaetoceros compressus Lauder & $\mathrm{PF}$ & $\mathrm{N}$ & Surirella fastuosa var. recendes (A.Schmidt)Cleve & $\mathrm{PF}$ & $\mathrm{T}$ \\
\hline Chaetoceros curvisetus Cleve & $\mathrm{F}$ & $\mathrm{N}$ & Surirella sp. & $\mathrm{E}$ & --- \\
\hline Chaetoceros decipiens Cleve & $\mathrm{E}$ & $\mathrm{O}$ & Synedra affinis Kützing & $\mathrm{E}$ & $\mathrm{T}$ \\
\hline Chaetoceros didymus Ehrenberg & $\mathrm{E}$ & $\mathrm{N}$ & Synedra gailloni (Bory) Erhenberg & $\mathrm{PF}$ & ES \\
\hline Chaetoceros diversus Cleve & $\mathrm{PF}$ & $\mathrm{N}$ & Synedra ulna (Nitzsch) Ehrenberg & $\mathrm{E}$ & $\mathrm{T}$ \\
\hline Chaetoceros lorenzianus Grunow & $\mathrm{F}$ & $\mathrm{N}$ & Synedra sp. & $\mathrm{E}$ & --- \\
\hline Chaetoceros peruvianus Brightwell & $\mathrm{PF}$ & $\mathrm{O}$ & Terpsinoe musica Ehrenberg & $\mathrm{E}$ & $\mathrm{T}$ \\
\hline Chaetoceros sp. & $\mathrm{F}$ & --- & Thalassiosira subtilis (Ostenfeld) Gran. & $\mathrm{E}$ & $\mathrm{O}$ \\
\hline Chaetoceros subtilis Cleve & $\mathrm{PF}$ & ES & Thalassionema frauenfeldii Grunow & $\mathrm{PF}$ & $\mathrm{O}$ \\
\hline Climacosphenia moniligera (Lyng.) Kütz. & $\mathrm{F}$ & $\mathrm{T}$ & Thalassionema nitzschioides Grunow & $\mathrm{F}$ & $\mathrm{O}$ \\
\hline Cocconeis scutellum Ehrenberg & $\mathrm{E}$ & $\mathrm{T}$ & Triceratium antediluvianum (Ehr.) Grunow & $\mathrm{F}$ & $\mathrm{T}$ \\
\hline Cocconeis sp. & $\mathrm{E}$ & --- & Triceratium pentacrinus Ehrenberg & $\mathrm{E}$ & $\mathrm{T}$ \\
\hline Corethron hystrix Hensen & $\mathrm{PF}$ & $\mathrm{O}$ & CHRYSOPHYTA & & \\
\hline Coscinodiscus centralis Ehrenberg & $\mathrm{F}$ & $\mathrm{O}$ & Dictyocha fibula Ehrenberg & $\mathrm{E}$ & $\mathrm{O}$ \\
\hline Coscinodiscus spp. & $\mathrm{PF}$ & --- & CHLOROPHYTA & & \\
\hline Cyclotella meneghiniana Kützing & $\mathrm{E}$ & $\mathrm{T}$ & Cladophora sp. & $\mathrm{E}$ & --- \\
\hline Cylindrotheca closterium (Ehr.) Reiman Lewis & $\mathrm{F}$ & $\mathrm{T}$ & Cylindrocapsa conferta W. West & $\mathrm{E}$ & $\mathrm{D}$ \\
\hline Dactyliosolen fragilissimus (Bergon) Hasle & $\mathrm{F}$ & $\mathrm{N}$ & Dictyosphaerium $\mathrm{sp}$. & $\mathrm{E}$ & --- \\
\hline Diploneis bombus Ehrenberg & $\mathrm{E}$ & $\mathrm{T}$ & Pediastrum boryanum (Turpin) Meneghini & $\mathrm{E}$ & $\mathrm{D}$ \\
\hline Diploneis sp. & $\mathrm{E}$ & --- & Pediastrum duplex Meyen & $\mathrm{PF}$ & $\mathrm{D}$ \\
\hline Entomoneis alata Ehrenberg & $\mathrm{F}$ & $\mathrm{T}$ & Scenedesmus acuminatus (Lagerch.) Chodat & $\mathrm{E}$ & $\mathrm{D}$ \\
\hline Fragilaria capucina Desmazières & $\mathrm{F}$ & $\mathrm{T}$ & Scenedesmus bicaudatus (Hansgirg) Chodat & $\mathrm{E}$ & $\mathrm{D}$ \\
\hline Fragilaria sp. & $\mathrm{PF}$ & --- & Scenedesmus perforatus Lemmermann & $\mathrm{E}$ & $\mathrm{D}$ \\
\hline Fragilaria striatula Lyngbye & $\mathrm{E}$ & $\mathrm{T}$ & Scenedesmus quadricauda (Turpin) Brébisson & $\mathrm{PF}$ & $\mathrm{D}$ \\
\hline Fragilaria vitrea (Kützing) Grunow & $\mathrm{E}$ & $\mathrm{T}$ & Scenedesmus sp. & $\mathrm{E}$ & --- \\
\hline Grammatophora hamulifera Kützing & $\mathrm{PF}$ & $\mathrm{T}$ & Staurastrum sp. & $\mathrm{E}$ & --- \\
\hline Grammatophora marina (Lyngbye) Kütz. & $\mathrm{F}$ & $\mathrm{T}$ & & & \\
\hline
\end{tabular}

Durante o período estudado foram registrados valores do índice de diversidade específica de 0,48 bits.cel $^{-1} \mathrm{em}^{-}$dezembro de 2005 (preamar; Boa Viagem) a 4,17 bits.cel ${ }^{-1}$ em julho de 2005 (baixa-mar; Boa Viagem), sendo que 50\% das amostras analisadas foram classificadas como alta diversidade, 41,67\% como baixa diversidade e $8,33 \%$ apresentando diversidade muito baixa (Fig. 6). Os menores valores de diversidade $\left(0,48\right.$ e 1,28 bits.cel $\left.^{-1}\right)$ estão relacionados à dominância de Helicotheca tamesis durante o mês de dezembro de 2005 e de Asterionellopsis glacialis durante junho de 2005.

A classificação das unidades amostrais por análise de agrupamento revelou a formação de dois grupos, considerados bem ajustados com valor cofenético de 0,8 (Fig. 7).
O grupo 1 compreendeu as espécies dominantes e muito frequentes durante o período de estiagem (com exceção de Asterionellopsis glacialis), classificadas como espécies marinhas planctônicas.

O grupo 2 foi mais diversificado quanto à distribuição ecológica, reunindo espécies planctônicas neríticas/oceânicas e espécies ticoplanctônicas marinhas, que obtiveram maior representatividade durante o período chuvoso. As diatomáceas Chaetoceros brevis e Chaetoceros compressus encontraram-se mais afastadas por terem sido registradas apenas no período de estiagem, sendo espécies planctônicas neríticas.

O plano fatorial 1-2 explicou $54,1 \%$ da variância dos dados (Fig. 8). No eixo 1 (36,5\%) projetaram-se positiva- 


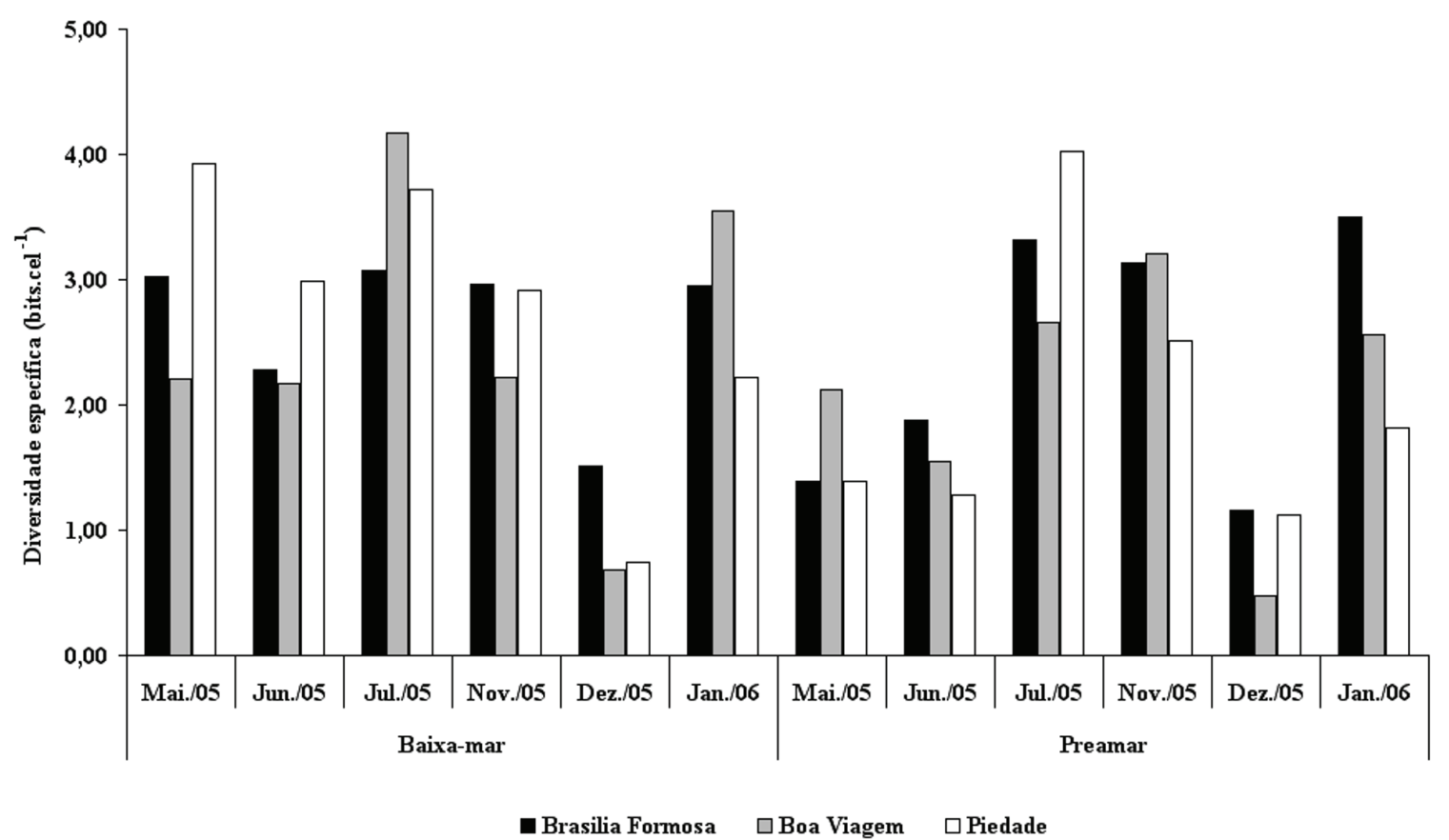

Figura 6. Índice de diversidade específica calculado para as praias de Brasília Formosa, Boa Viagem e Piedade, durante a baixa-mar (BM) e preamar (PM) do período chuvoso (maio, junho e julho/05) e de estiagem (novembro, dezembro/05 e janeiro/06).

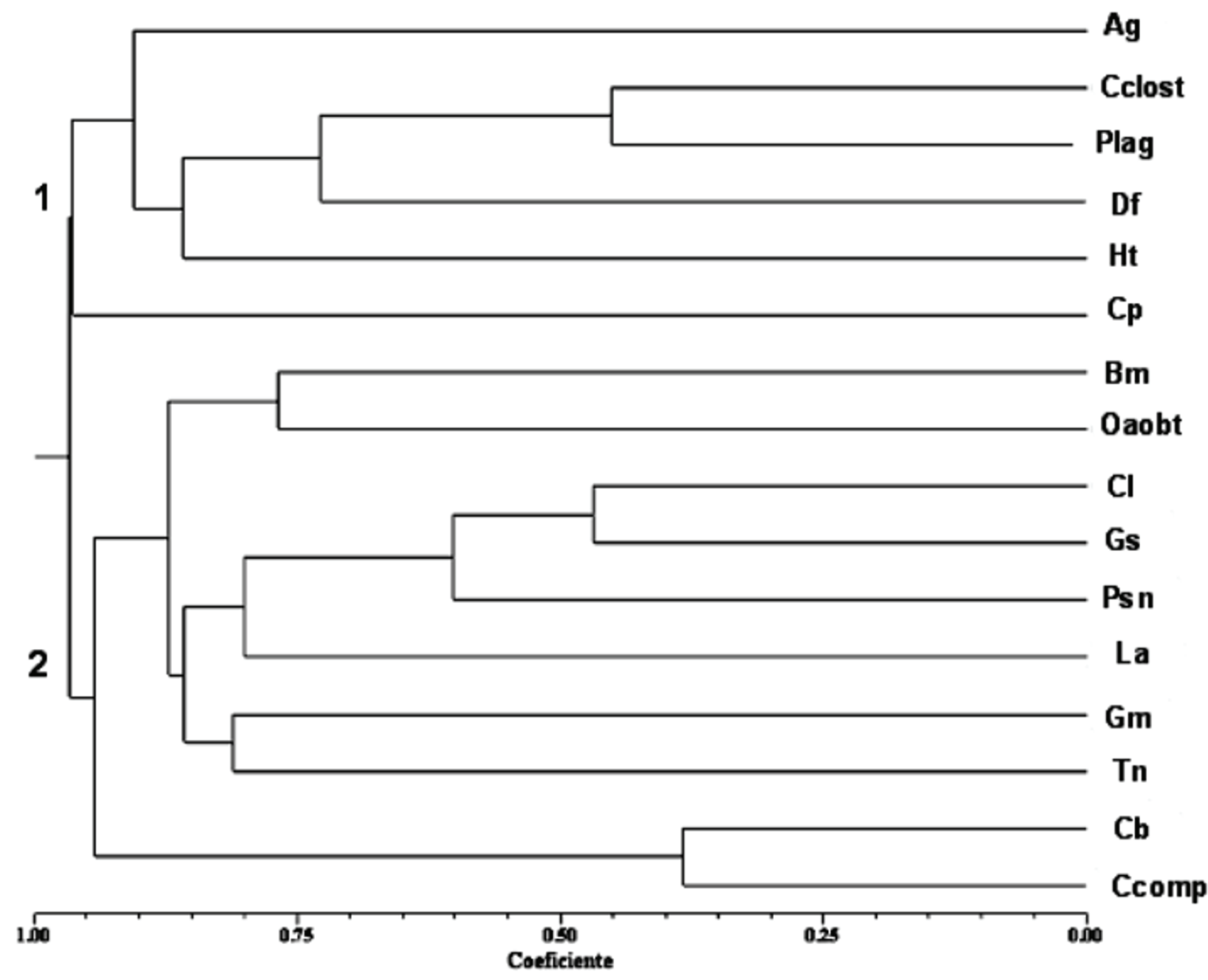

Figura 7. Dendrograma das associações das espécies do fitoplâncton mais representativas na área de estudo - Ag: Asterionellopsis glacialis, Bm: Bellerochea malleus, Cp: Cerataulina pelagica, Cb: Chaetoceros brevis, Ccomp: Chaetoceros compressus, Cl: Chaetoceros lorenzianus, Cclost: Cylindrotheca closterium, Df: Dactyliosolen fragilissimus, Gm: Grammatophora marina, Gs: Guinardia striata, Ht: Helicotheca tamesis, La: Licmophora abbreviata, Oaobt: Odontella aurita var. obtusa, Plag: Plagiogramma sp, Psn: Pseudo-nitzschia sp, Tn: Thalassionema nitzschioides. 


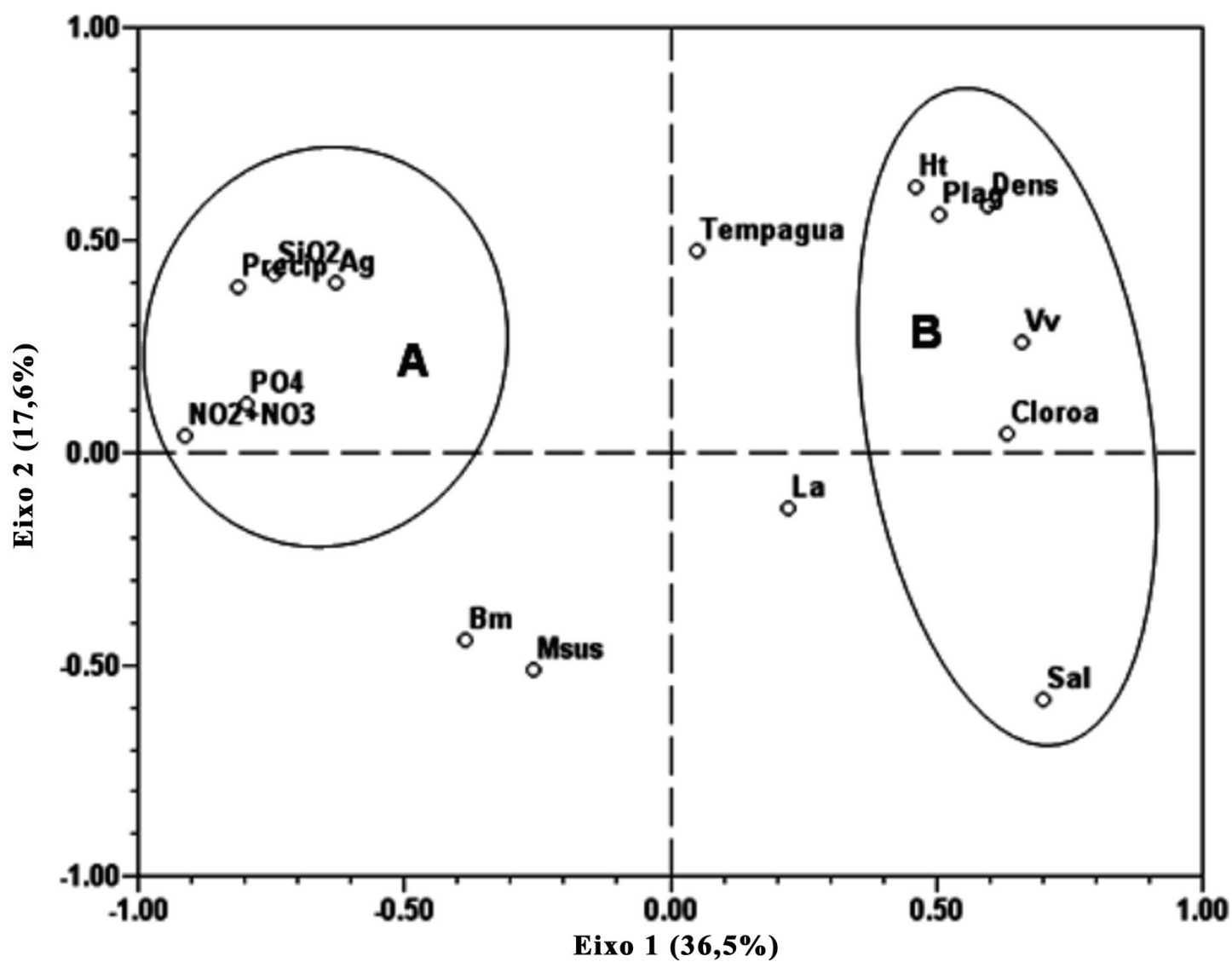

Figura 8. Análise dos componentes principais. Códigos: temperatura da água (Tempagua), salinidade (Sal), nitrito e nitrato (NO2+NO3), fosfato (PO4), silicato (SiO2), precipitação (Precip), material em suspensão (Msus), velocidade dos ventos (Vv), clorofila a (Cloroa), densidade (Dens), Asterionellopsis glacialis (Ag), Helicotheca tamesis (Ht), Licmophora abbreviata (La) e Plagiogramma sp. (Plag).

mente a salinidade, clorofila $a$, densidade e a velocidade dos ventos. Em oposição, destacaram-se a precipitação pluviométrica, nitrito + nitrato, fosfato, silicato e a diatomácea Asterionellopsis glacialis, no lado negativo. Apesar da baixa correlação com o eixo $(\mathrm{d}<0,5)$, a temperatura da água e a diatomácea Licmophora abbreviata posicionaramse no lado positivo.

No eixo $2(17,6 \%)$ posicionaram-se significativamente apenas as diatomáceas Helicotheca tamesis e Plagiogramma sp., no lado positivo. Apesar da baixa correlação com o eixo $(\mathrm{d}<0,5)$, a diatomácea Bellerochea malleus e o material em suspensão posicionaram-se no lado negativo.

\section{Discussão}

A estrutura das populações do fitoplâncton encontrase diretamente relacionada às características físicas e químicas da água conjuntamente com outros fatores ambientais, os quais, agindo unidos ou isoladamente, condicionam o estabelecimento de populações adaptadas a estas variações (Phlips et al. 2002). Na costa pernambucana, mudanças temporais na distribuição e abundância do fitoplâncton são reguladas principalmente pela eutrofização, descarga dos rios, ciclo de maré e precipitação
(Paranaguá 1985/86; Neumann-Leitão et al. 1991/93; Eskinazi-Leça et al. 1997).

Alguns trabalhos realizados em outras zonas litorâneas identificaram também o efeito do vento (Gómez-Erache et al. 2000), influência da maré (Villate 1997), pressão atmosférica, temperatura da água (Licandro \& Ibanez 2000) e sazonalidade (Khalil \& El-Rahman 1997; Villa et al. 1997; Totti et al. 2000) controlando a distribuição e composição das comunidades do plâncton.

A relação positiva entre o material em suspensão e nutrientes sugere que a contribuição desses elementos para a zona de arrebentação é resultado principalmente da ressuspensão próxima à costa, propiciada pela ação de ventos onshore e pela alta precipitação pluviométrica. As dunas costeiras também contribuem para um incremento de nutrientes na zona de arrebentação, pois estas normalmente possuem aqüíferos associados, que carregam altas concentrações de nitrato, fonte do maior requerimento das diatomáceas (McLachlan \& Illenberger 1986).

Na praia de Rio Doce e Casa Caiada (PE), condições similares causaram um aumento na densidade do fitoplâncton, ocasionada por espécies oportunistas (ou r-estrategistas). Esta situação esteve associada aos altos valores dos 
parâmetros abióticos (turbidez e sais nutrientes) na maré baixa em áreas abrigadas, principalmente em Rio Doce. Nas preamares ocorreu uma diminuição na concentração dos nutrientes e da densidade fitoplanctônica, devido à entrada de água da plataforma continental adjacente (Pereira et al. 200Durante o período de estiagem, a clorofila $a$ e a densidade fitoplanctônica apresentaram uma correlação inversa com a precipitação e com os nutrientes, e direta com a salinidade e a velocidade do vento. Nessa situação, a drenagem terrestre é muito mais amena e as condições hidrológicas tornam-se favoráveis ao florescimento estival. Desta forma, o impacto terrígeno influi significativamente no comportamento fitoplanctônico, inibindo o crescimento da flora planctônica no período chuvoso e determinando um comportamento inverso durante o período de estiagem (Eskinazi-Leça et al. 1997; Koening \& Eskinazi-Leça 1991; Koening et al. 2003).

Apesar dos elevados valores de diversidade específica, períodos de baixa diversidade ocorreram, relacionados, principalmente, pela dominância de duas espécies: A. glacialis, nos meses de chuva e H. tamesis, na estação seca. Segundo Barretto (dados não publicados) estas espécies são consideradas como oportunistas por apresentarem elevada abundância em águas ricas em nutrientes e por se beneficiarem da turbulência, que faz com que elas sejam ressuspensas. Organismos com essas estratégias de sobrevivência são caracterizados por apresentarem rápidas taxas de crescimento, possuir elevada razão superfície/volume e alta atividade metabólica, adaptando-se mais rapidamente às condições locais.

Nas praias estudadas, os altos valores de abundância de $A$. glacialis não estiveram relacionados aos ventos de sul/sudeste. No período que essa espécie apresentou seus maiores valores, os ventos vindos do norte foram predominantes. Provavelmente, outros fatores estavam favorecendo a dominância desse organismo.

Brown \& McLachlan (1990) afirmam que altas concentrações de diatomáceas são observadas na zona de arrebentação de praias arenosas do mundo todo, entre as latitudes $40^{\circ} \mathrm{N}$ e $40^{\circ} \mathrm{S}$. Essas populações abastecem numerosas cadeias alimentares e podem ser acumuladas à superfície formando manchas marrons escuras. A ocorrência dessas manchas está relacionada a mecanismos endógenos fisiológicos das células e ao hidrodinamismo destes ambientes (Talbot et al. 1990).

Na região sul do Brasil, a ocorrência de manchas esteve associada, principalmente, a Asterionellopsis glacialis. O primeiro registro deste evento foi na praia do Cassino (RS) onde essas densas e freqüentes acumulações foram tratadas primordialmente como um florescimento clássico (Aguiar \& Corte-Real 1973; Rosa \& Aguiar 1973). Posteriormente estudos mais específicos sugeriram um padrão sazonal na ocorrência destas manchas, associada com a precipitação e ventos onshore (Gianuca 1983; Odebrecht et al. 1995). Em Santa Catarina, na praia dos Navegantes, Rörig et al. (1997) observaram uma co-ocorrência de Asterionellopsis glacialis e Anaulus australis, padrão semelhante ao encontrado em praias da África do Sul (Talbot et al. 1990).

No Nordeste do Brasil, na praia do Futuro (CE), ocorreram florações formando manchas das diatomáceas $A$. glacialis e Eunotogramma sp. no período chuvoso, com densidades de $1,9 \times 10^{4}$ céls. $L^{-1}$ (Tahim et al. 1990).

Vários fatores ambientais têm sido envolvidos para explicar esses fenômenos na zona de arrebentação, entretanto, Talbot et al. (1990) afirmam que nem toda praia arenosa tem florescimentos com acumulação de diatomáceas e que estas formações possuem fatores controladores ainda não confirmados. Outros autores apontam que as características físicas desses ecossistemas são os principais responsáveis pela presença ou ausência dessas acumulações, destacando a largura da zona de arrebentação, presença de correntes longitudinais, dunas costeiras, aporte de águas subterrâneas e regime meteorológico com fortes ventos do sul/sudeste, que podem estar associados com a acumulação de diatomáceas nestes locais (Campbell \& Bate 1996; Campbell \& Bate 1997; Odebrecht et al.1995; Odebrecht et al. 2003).

Em Algoa Bay e ao longo da costa de Washington e Oregon, o estado energético da zona de arrebentação foi considerado como controlador da ausência e presença das acumulações das diatomáceas. Segundo Talbot \& Bate (1987), quando o estado de energia da praia é baixo, as acumulações desaparecem devido à redução das bolhas internas das ondas necessárias para a ressuspensão das células à superfície. Um estado contínuo de baixa energia das praias é um meio de prevenir a formação dessas acumulações.

Rezende \& Brandini (1997) relacionam as alterações ambientais (diminuição da temperatura da água e ventos de direção sul) decorrentes da passagem de frentes frias, que assolam frequentemente as águas costeiras da região sul do Brasil, como responsáveis pelo padrão de distribuição dos organismos fitoplanctônicos na zona de arrebentação. Segundo Rörig \& Garcia (2003), essas frentes frias condicionam um ciclo de transporte vertical de células do sedimento para a coluna d'água e, em condições calmas, o retorno para o sedimento, indicando um estágio bêntico durante seu ciclo de vida. Esse fato pode explicar a dominância de $H$. tamesis no período de estiagem, onde $A$. glacialis, mesmo sendo muito freqüente durante o estudo, obteve baixos valores de abundância.

Apesar da ocorrência de florescimentos esporádicos de algumas diatomáceas características da zona de arrebentação, a morfologia praial, hidrodinamismo, velocidade e direção dos ventos não favoreceram a formação de manchas devido à acumulação das mesmas, como ocorre no sul do país.

\section{Agradecimentos}

Ao Conselho Nacional de Desenvolvimento Científico e Tecnológico (CNPq) pela concessão da bolsa de estudo para o primeiro Autor. 


\section{Referências Bibliográficas}

Aguiar, L.W. \& Corte-Real, M. 1973. Sobre uma floração de Asterionella japonica Cleve (1878) na costa do Rio Grande do Sul. Iheringia, Série Botânica 17: 18-27.

Aragão, J.O.R. 2004. A influência dos oceanos Pacífico e Atlântico na dinâmica do tempo e do clima do Nordeste do Brasil. Pp. 287-317. In: Eskinazi-Leça, E.; Neumann-Leitão, S. \& Costa, M.F. (org.) Oceanografia - Um cenário tropical. Recife, Bagaço.

Bray, R.J. \& Curtis, J.T. 1957. An ordination of the upland forests communities of Southern Wisconsin. Ecology Monographs 27: 325-349.

Branco, E.S. 2008. Influência das variáveis ambientais na comunidade fitoplanctônica estuarina. Série Teses e Dissertações. Recife, Editora Universitária da Universidade Federal de Pernambuco.

Brown, A.C. \& McLachlan, A. 1990. Beach and surf-zone flora. Pp. 41-50. In: A.C. Brown \& A. McLachlan (eds). Ecology of Sandy Shores. Netherlands, Elsevier Science.

Campbell, E.E. 1996. Groundwater as a possible controller of surf diatom biomass. Revista Chilena de Historia Natural 69: 503-510.

Campbell, E.E. \& Bate, G.C. 1997. Coastal features associated with diatom discoloration of surf-zones. Botanica Marina 40: 179-185.

Eskinazi, E. \& Satô, S. 1963/64. Contribuição das diatomáceas da praia de Piedade (Pernambuco - Brasil). Trabalhos Oceanográficos 5/6: 73-114.

Eskinazi-Leça, E.; Silva-Cunha, M.G.G.; Koening, M.L.; Macêdo S.J. \& Costa, K.M.P. 1997. Variação espacial e temporal do fitoplâncton na plataforma continental de Pernambuco - Brasil. Trabalhos do Instituto de Oceanografia da Universidade Federal de Pernambuco 25: 1-16.

Ferrario, M.; Sar, E. \& Sala, S. 1995. Metodologia básica para el estudio del fitoplancton con especial referencia a las diatomaceas. Pp.1-24. In: K. Alvear; M. Ferrario; E.C. Oliveira-Filho \& E. Sar (eds.). Manual de Métodos Ficológicos. Concepción, Universidad de Concepción.

Gianuca, N.M. 1983. A preliminary account of the ecology of sandy beaches in Southern Brazil. Pp. 413-419. In: A. McLachlan, \& T. Erasmus (eds). Sandy Beaches as Ecosystems. Junk, The Hague.

Gómez-Erache, M.W.; Norbis W. \& Bastreri, D. 2000. Wind effect as forcing factor controlling distribution and diversity of copepods in a shallow temperate estuary (Solis Grande, Uruguay). Scientia Marina 64(1): 87-95

Grasshoff, K.; Enrhardt, M. \& Kremling, K. 1983. Methods of Seawater Analysis. 2nd ed. New York, Verlag Chemie.

Harris, G.P. 1986. Phytoplankton ecology: structure, function and fluctuation. New York, Chapman and Hall.

Hasle, G.R. 1978. The inverted-microscope methods. Pp. 88-96. In: A. Sournia (ed.). Phytoplankton Manual. Paris, UNESCO.

Hoek, C.V.D; Mann, D.G. \& Jahns, H.M. 1995. Algae: an introduction to phycology. Cambridge, Cambridge University Press.

Khalil, M. \& El-Rahman, N.A. 1997. Abundance and diversity of surface zooplankton in the Gulf of Aqaba, Red Sea, Egypt. Journal of Plankton Research 19: 927-936.

Knoppers, B.A.; Ekau, W.; Figueiredo Júnior, A.G. \& Soares Gomes, A. 2002. Zona costeira e plataforma continental do Brasil. Pp. 353-361. In: Pereira, R.C \& Soares Gomes, A. (org.) Biologia Marinha. Rio de Janeiro, Interciência.

Koening, M. L. \& Eskinazi Leça, E. 1991. Aspectos quantitativos do fitoplâncton na área estuarina de Suape (PE). Pp. 36-55. In: Anais do IV Encontro Brasileiro de Plâncton. Recife, Editora Universitária da Universidade Federal de Pernambuco.

Koening, M. L.; Eskinazi Leça, E.; Neumann-Leitão, S. \& Macedo, J.S. 2003. Impacts of the construction of the Port of Suape on phytoplankton in the Ipojuca River estuary (Pernambuco-Brazil). Brazilian Archives Biology Technology 46(1): 3-81.

Licandro, P. \& Ibanez, F. 2000. Changes of zooplankton communities in the Gulf of Tigullio (Ligurian Sea, Western Mediterranean) from 1985 to 1995, influence of hydroclimatic factors. Journal of Plankton Research 22(12): 2225-2253.

Lobo, E. \& Leighton, G. 1986. Estructuras comunitarias de las fitocenosis planctonicas de los sistemas de desembocaduras de rios y esteros de la zona central de Chile. Revista Biologia 22: 1-29.
Margalef, R. 1978. Les types biologiques de phytoplankton consideres comme des alternatives de survie dans um millieu instable. Ocoeanologica Acta 4(1): 493-509.

Margem, H.; Albuquerque, E.; Dalto, A. \& Machado, M.C. 2003. Mycrophytobenthic and phytoplanktonic biomass of the surf zone of two exposed sandy beaches. Journal of Coastal Research 35: 402-407.

McLachlan, A. \& Illenberger, W.K. 1986. Significance of ground water nitrogen input to a beach/surfzone ecosystem. Stygologia 3: 291-296.

Nascimento, F.C.R.; Muniz, K.; Feitosa, F.A.N.; Araújo, J.P.; Silva, R.M.S.; Sônia da Silva, G. \& Flores Montes, M.J. 2003. Disponibilidade nutricional da Bacia do Pina e rio Tejipió (Recife - PE, Brasil) em relação aos nutrientes e biomassa primária (Setembro/2000). Tropical Oceanography 31: 149-169.

Neumann-Leitão, S.; Gusmão, L.M.O.; Nogueira-Paranhos, J.D.; Nascimento-Vieira, D.A. \& Paranaguá, M.N. 1991/93. Zooplâncton da plataforma continental norte do estado de Pernambuco (Brasil). Trabalhos Oceanográficos 22: 97-116.

Newell, G.H. \& Newell, R. 1963. Marine Plankton: a practical guide. London, Hutchinson Educat.

Odebrecht, C. \& Abreu, P. C. 1997. Microorganismos em praias arenosas expostas: importância, aspectos metodológicos e estado da arte para o sul do Brasil. Oecologia Brasiliensis 3: 2-18

Odebrecht, C.; Segatto, C. V. \& Fresitas, C. A. 1995. Surf-zone cloropyll a variability at Cassino Beach, Southern Brazil. Estuarine, Coastal and Shelf Science 41: 81-90

Odebrecht, C.; Abreu, P.C.; Fujita, C.C. \& Bergesch, M. 2003. The impact of mud deposition on the long term variability of the surf-zone diatom Asterionellopsis glacialis (Castracane) Round at Cassino Beach, Brazil. Journal of Coastal Research 35: 486-491.

Paranaguá, M.N. 1985/86. Zooplankton of the Suape area (PernambucoBrazil). Trabalhos Oceanográficos 19: 113-124

Pereira, L.C.C.; Jiménez, J.A. \& Medeiros, C. 2003. Environmental degradation of the littoral of Casa Caiada and Rio Doce, Olinda-PE (Brazil). Journal of Coastal Research 35: 502-508.

Pereira, L.C.C.; Jiménez, J.A.; Koening, M.L.; Porto Neto, F.F.; Medeiros, C. \& Costa, R.M. 2005. Effect of Coastline Properties and Wastewater on Plankton Composition and Distribution in a Stressed Environment on the North Coast of Olinda-PE (Brazil). Brazilian Archives of Biology and Technology 48(6): 1013-1026.

Phlips, J.E.; Badylak, S. \& Grosskopf, T. 2002. Factors Affecting the Abundance of Phytoplankton in a Restricted Subtropical Lagoon, the Indian River Lagon. Estuarine, Coastal and Shelf Science 55: 385-402.

Rezende, K.R.V. \& Brandini, F.P. 1997. Variação sazonal do fitoplâncton da zona de arrebentação da praia de Pontal do Sul (Pontal do ParanáPR). Nerítica 11: 49-62

Rohlf, F.J. \& Fisher, D.L. 1968. Test for hierarchical structure in random data sets. Systematic Zoologic 17: 407-412.

Rollnic, M.; Medeiros, C. 2006. Circulation of the Coastal Waters of Boa Viagem, Piedade and Candeias Beaches-PE, Brazil. Journal of Coastal Research 39: 648-650.

Rörig, L.R. \& Garcia, V.M.T. 2003. Accumulations of the surf-zone diatom Asterionellopsis glacialis (CASTRACANE) ROUND in Cassino Beach, Southern Brazil, and its relationship with environmental factors. Journal of Coastal Research 35: 167-177.

Rörig, L.R ; Resgalla Jr., C. ; Pezzuto, P.R ; Alves, E.S. \& Morelli, F. 1997. Análise ecológica de um processo de acumulação da diatomaceae Anaulus sp. na zona de arrebentação da praia dos Navegantes (Santa Catarina, Brasil). Oecologia Brasiliensis 3: 29-43.

Rörig, L.R; Almeida, T.C.M. \& Garcia, V.M.T. 2006. Structure and succession of the surf-zone phytoplankton in casino beach, southern Brazil. Journal of Coastal Research 39: 1246-1250.

Rosa, Z.M \& Aguiar, L.W. 1973. Diatomáceas da costa do Rio Grande do Sul, Brasil: I- praia do Cassino - Rio Grande. Iheringia 21: 103-128.

Satô, S.; Paranaguá, M.N. \& Eskinazi, E. 1963/64. On the mechanism of red tide of Trichodesmium in Recife Northeastern Brazil, with some considerations of the relation to the human disease, "Tamandaré fever". Trabalho do Instituto Oceanográfico Universidade do Recife 5/6: 7-49. 
Shannon, L.E. 1948. A mathematical theory of communication. Bulletin of System Tecnology Journal 27: 379-423.

Strickland, J.D.H. \& Parsons, T.R.A. 1972. Manual of Seawater Analysis. Bulletin Fisheries Research Board of Canada 167: 1-205.

Tahim, E.F.; Verde, N.G.L. \& Eskinazi-Leça, E. 1990. Florescimento de algas planctônicas na praia do Futuro (Fortaleza-CE). Pp. 117-122. In: Anais do IV Encontro Brasileiro de Plâncton. Recife, Editora Universitária da Universidade Federal de Pernambuco.

Talbot, M.M.B. \& Bate, G.C. 1987. Rip current characteristics and their role in the exchange of water and surf diatoms between the surf zone and nearshore. Estuarine, Coast and Shelf Science 25: 707-720.

Talbot, M.M.B.; Bate, G.C. \& Campbell, E.E. 1990 A review of the ecology of surf zone diatoms, with special reference to Anaulus australis. Oceanography and Marine Biology. An Annual Review 28: 155-175.
Totti, C.; Civitarese, G.; Acri, F.; Barletta, D.; Candelari, G.; Paschini, E. \& Solazzi, A. 2000. Seasonal variability of phytoplankton populations in the middle Adriatic sub-basin. Journal of Plankton Research 22(9): 1735-1756.

Utermöhl, H. 1958. Zur vervollkommnung der quantitativen Phytoplankton Methodik. Mitteilung Internationale Vereinigung für Theoretische Angewandte Limnologie 9: 68-72.

Villa, H.; Quintela, J.; Coêlho, M.L.; Icely, J.D. \& Andrade, J.P. 1997. Phytoplankton biomass and zooplankton abundance on the south coast of Portugal (Sagres), with special reference to spawning of Loligo vulgaris. Scientia Marina 61 (2): 123-129.

Villate, F. 1997. Tidal influence on zonation and occurrence of resident and temporary zooplankton in a shallow system (Estuary of Mundaka, bay of Biscay). Scientia Marina 61 (2): 173-188. 